Dokuz Eylül Üniversitesi-Mühendislik Fakültesi Fen ve Mühendislik Dergisi Cilt 20, Sayı 60, Eylül, 2018
Dokuz Eylul University-Faculty of Engineering Journal of Science and Engineering Volume 20, Issue 60, September, 2018

DOI: $10.21205 /$ deufmd. 2018206073

\title{
Karbon Fiber/ZnO Fotokatalizörlerin Üretimi ve Karakterizasyonu
}

\section{Mustafa EROL ${ }^{* 1}$}

1Dokuz Eylül Üniversitesi, Mühendislik Fakültesi, Metalurji ve Malzeme Mühendisliği Bölümü, 35390, Buca, İzmir. (ORCID: 0000-0002-3257-4418)

(Alınıș / Received: 22.01.2018, Kabul / Accepted: 18.06.2018 Online Yayınlanma / Published Online: 15.09.2018

Anahtar Kelimeler Özet: $\mathrm{Bu}$ çalışmada farklı $\mathrm{Zn}^{2+}$ derişimlerine sahip başlangıç $\mathrm{ZnO}$,

Karbon Fiber, Fotokatalitik, Sol-jel çözeltileri sol-jel daldırma kaplama yöntemi ile ticari karbon fiberler üzerine kaplanmıștır. Yapının kristalinitesini artırabilmek ve $\mathrm{ZnO}$ film oluşumunu sağlamak amacıyla $300^{\circ} \mathrm{C}$ 'de 1 saat süreyle ısıl işlem uygulanmıştır. Elde edilen karbon fiber/ZnO yapılar artan başlangıç çözeltisi derişimine bağlı olarak düzenli ve homojen morfolojik özellikler sergilemiştir. Başlangıç $\mathrm{Zn}^{2+}$ derişimin artması, karbon fiber/ ZnO yapısının metilen mavisi sulu çözeltilerinin fotokatalitik parçalanmasında etkin rol oynamıştır. En yüksek fotokatalitik parçalanma hızı $25.10^{-4} \mathrm{M} \mathrm{Zn}^{2+}$ derişimine sahip çözelti kullanılarak üretilen karbon fiber/ZnO ile 1,39 $\mathrm{sa}^{-1}$ olarak elde edilmiştir.

\section{Production and Characterization of Carbon Fiber/Zno Photocatalyst}

\begin{tabular}{ll}
\hline Keywords & Abstract: In this study, initial solutions with different $\mathrm{Zn}^{2+}$ \\
ZnO, & concentrations were deposited on commercial carbon fibers by the \\
Carbon Fiber, & sol-gel dip coating method. Heat treatment was applied at $300{ }^{\circ} \mathrm{C}$ \\
Photocatalysis, & for 1 hour in order to improve the crystallinity of the structure and \\
Sol-gel & to provide ZnO film formation. The resulting carbon fiber/ZnO \\
& structures exhibited regular and homogeneous morphological \\
& properties due to the increased initial solution concentration. The \\
& increase of initial $\mathrm{Zn}^{2+}$ concentration has played an active role in \\
& the photocatalytic degradation of aqueous solutions of methylene \\
& blue of carbon fiber/ZnO structure. The highest photocatalytic \\
& decomposition rate was obtained as $1.39 \mathrm{~h}^{-1}$ with carbon fiber / \\
& ZnO produced using a solution with $25.10-4 \mathrm{M} \mathrm{Zn}^{2+}$ concentration.
\end{tabular}

*Sorumlu yazar: mustafa-erol@outlook.com 


\section{Giriş}

Fujishima ve Honda'nın 1972 yılında suyun fotolizi üzerine titanyum dioksit kullanarak gerçekleştirdikleri öncü çalışmadan günümüze fotokatalitik çalışmalar her geçen gün artarak devam etmektedir [1]. Fotokataliz, bir $1 s ̧ \mathrm{k}$ kaynağı ile uyarılan yarı iletkenin, foto uyarılmış elektron ve boşluklar sayesinde oluşturduğu oksitleyici yüzeyde organik ve toksik bileşenlerin yok edilmesi şeklinde tanımlanabilir [2].

Literatürde fotokatalitik aktivite gösteren birçok yarı iletken malzeme bulunmaktadır. Bunların başlıcaları, $\mathrm{TiO}_{2}$, CdS, ZnS, $\mathrm{SrTiO}_{3}, \mathrm{ZnO}$ v.b. șeklinde sıralanabilir [3]. Bu fotokatalizörlerin arasında $\mathrm{ZnO}$, düșük maliyeti, yüksek redoks potansiyeli, toksik olmayışı ve çevre dostu oluşu gibi özellikleri ile oldukça ilgi çekmiştir [4]. Buna karşın sahip olduğu geniş bant aralığı $(3,37 \mathrm{eV})$, çinko oksitin aktivitesini görünür bölgede düşürmektedir. $\mathrm{Bu}$ nedenle birçok çalışmada metal ve metal olmayan katkılar ile bant aralığı düşürülmeye ve böyle görünür bölge aktivitesi artırılmaya çalışılmıştır. Yapıya giren katkı elemanı ZnO yapısını bozarak, iletim veya değerlik bandının konumunu değiștirmekte böylece aktiviteyi artırmaktadır [5].

Metal veya metal olmayan katkılara ek olarak son yıllarda çeşitli karbon yapılarla çinko oksitin bir araya getirildiği yüksek verimli katalizörler geliștirilmektedir. İletken özelliğe sahip karbon yapı, elektron geçişi için enerji basamağı oluşturarak foto elektron transferini hızlandırırken elektron boşluk birleșimini de yavaşlatmakta böylece katalitik etkinliği artırmaktadır [6]. Genellikle laboratuvar ortamında sentezlenmiş ve yüksek maliyetli karbon türevlerinin kullanıldığı bu çalışmalarda, karbon nanotüp [7], grafen [8], karbon siyahı [9], grafit [10], karbon fiber [11] gibi karbon türevlerinin çinko oksit ile çeşitli üretim yöntemleri sayesinde bir araya getirilmesi ile verimi artırılmış fotokatalizörler geliştirilmektedir.
Literatür bilgileri ışığında bu çalışmada ise, düşük maliyetli ve genellikler kompozit malzemelerde mukavemet artırıcı takviye elamanı rolünü üstlenen ve ticari olarak temin edilebilen karbon fiberlerin üzerinde sol-jel yöntemi ile $\mathrm{ZnO}$ ince filmlerin farklı $\mathrm{Zn}^{2+}$ derişime sahip başlangıç çözeltilerinin film oluşumuna etkileri ve geliştirilen karbon fiber/ZnO fotokatalitik özellikleri araștırılmıştır.

\section{Materyal ve Metot}

Karbon fiber/ZnO yapıların elde edilmesi için ilk olarak, üç farklı $\mathrm{Zn}^{2+}$ derişimine sahip çözelti sol-jel yöntemiyle üretilmiştir. $\mathrm{Bu}$ amaçla, başlangıç malzemesi olarak Çinkoasetatdihidrat (Aldrich, \% 99.998) çözelti $\mathrm{Zn}^{+}$ derişimleri $1.10^{-4} \mathrm{M}, 5.10^{-4} \mathrm{M}$ ve $25.10^{-4} \mathrm{M}$ olacak şekilde $100 \mathrm{~mL}$ methanol (Aldrich, \% 99.8) ve $3 \mathrm{~mL}$ propionik asit (Aldrich, $\%$ 99.5) içerisinde, sırasıyla manyetik karıștırıcı ve ultrasonik banyo kullanılarak yaklaşık 20 dakika süre ile homojen ve saydam çözeltiler elde edilinceye kadar karıştırılmıştır. Çözelti hazırlama işlemini takiben, ticari olarak temin edilen karbon fiberler (Aksaca, 12K A-42) $10 \mathrm{~cm}$ boyda kesilerek ultrasonik karıştırıcı ile methanol içerisinde temizlenmiştir ve ardından sıcak hava ile kurutulmuştur. Bir sonraki aşamada ise fiberler üzerine daldırma kaplama yöntemi ile ince filmler uygulanmıştır. Daldırma kaplama işleminde, çözelti içerisinde bekleme süresi 10 saniye olarak uygulanmıştır. Kaplama işleminin ardından elde edilen filmler etüv ortamında $\quad 150 \quad{ }^{\circ} \mathrm{C}^{\prime}$ de $\quad 10$ dakika kurutulmuştur. Bu işlem her üç derişim ve ilgili numuneler için 10 kez uygulanmıștır. Son kat kaplama işleminin ardında, çinko oksit yapının oluşabilmesi için $300^{\circ} C^{\prime}$ de 1 saat ısıl işlem uygulanmış böylece filmlerin kristalinitesinin artırılması hedeflenmiştir.

Üretilen ince filmlerin yüzey ve kesit morfolojileri taramalı elektron mikroskobu (SEM, Zeiss-Sigma 300VP) ile 
elde edilmiştir. Üretilen filmlerin kristal yapıları X ışınları difraktometresi (XRD, Bruker, D2 Phaser ) ile $40 \mathrm{kV}$ ve $36 \mathrm{~mA}$ değerlerinde $\mathrm{CuK} \alpha \quad$ radyasyonu kullanılarak tespit edilmiştir.

Karbon Fiber/ZnO yapıların fotokatalitik parçalanma deneyleri başlangıç derişimi bilinen metilen mavisi sulu çözeltilerinin, sirküle hava soğutmalı bir fotokataliktik reaktörde Uv-vis ışık kaynağı (Osram, UltraVitalux E27) altında gerçekleştirilmiştir. Kullanılan 1 şı kaynağının görünür bölge ortalama ışıma şiddeti $18 \mathrm{~W} / \mathrm{m}^{2}$, UV-A 0,004 W/m², UV-B $0,004 \mathrm{~W} / \mathrm{m}^{2}$ ve UV-C $0,004 \mathrm{~W} / \mathrm{m}^{2}$ şeklindedir.

Metilen mavisi sulu çözeltileri 664 nm dalga boyunda belirgin bir optik soğurma piki vermektedir [12]. Bu pikin şiddetindeki fotokatalitik parçalanma sonucu zamana bağlı azalma spektrofotometre (UV-1240 Shimadzu UV/VIS) üzerinden tespit edilmiştir. Lambert Beer yasası bir çözeltinin derişimi ile belirli bir dalga boyundaki soğurma değerleri arasında doğrusal bir ilişki olduğunu ifade etmektedir [13]. Bu ilişki sayesinde, $664 \mathrm{~nm}$ için ölçülen metilen mavisi soğurma değerleri derişim değerlerine dönüştürülebilir. Bir önceki çalışmada deneysel olarak belirlenen $\mathrm{y}=68254,54 \mathrm{X} \quad(\mathrm{y}: 664 \mathrm{~nm}$ soğurma, $\mathrm{x}$ : molarite) ilişkisini kullanarak ölçülen soğurma değerleri, derişimler hesaplanmıştır [14]. Böylece, zamana bağlı derişim değişimi eğrilerinden yararlanarak her bir katalizörün aktivitesi, tepkime hızları üzerinden tespit edilmiştir.

\section{Bulgular}

Kaplama ve ısıl işlem ardından ilk olarak üretilen filmlerin yapısal özelliklerinin ve faz tayini yapılması amacı ile XRD desenleri elde edilmiştir.

$1.10^{-4} \mathrm{M}, 5.10^{-4} \mathrm{M}$ ve $25.10^{-4} \mathrm{M}$ derişimli çözeltilerden elde edilen kaplamalara ait numuneler sirasiyla M1, M5 ve M25 olarak kodlanmıştır.
Şekil 1.'de filmlere ait desenler yer almaktadır. Altlı etkisinin gösterilebilmesi için ayrıca kaplamasız fibere ait desen de şekilde görülmektedir. Her üç numuneye ait XRD desenlerinde görüldügü gibi, ince filmler başarılı bir şekilde üretilmiștir. Karbon Fiber/ZnO şeklindeki yapı karbon ve ZnO ikilisine ait JCPDS: 01-073-5918 ve JCPDS: 00-0361451 kırınım pikleri ile tam uyum sergilemiştir.

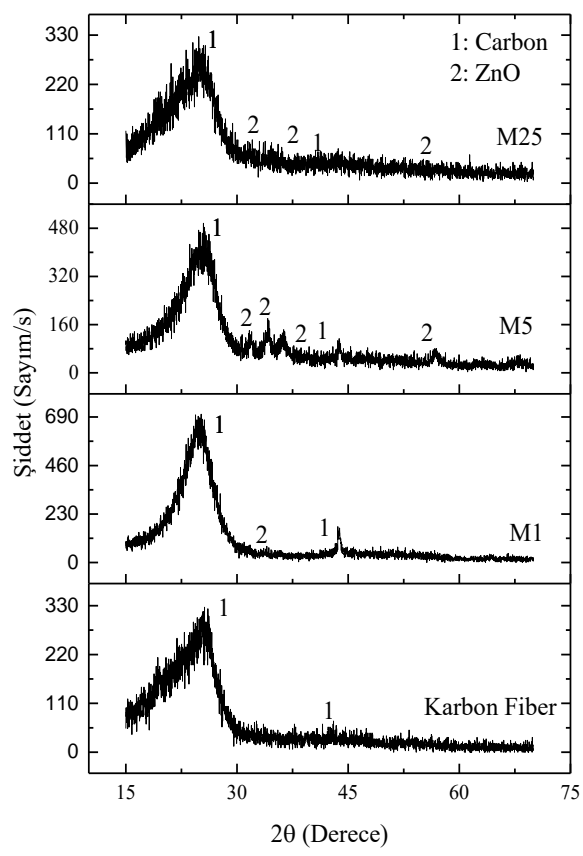

Şekil 1. Karbon Fiber/ZnO numunelerin XRD desenleri.

Numunelere ait taramalı elektron görüntüleri Şekil 2.'de verilmiştir. Başlangıç çözeltisinin derişimin artması ile birlikte, kaplanan bölge yoğunluklarındaki artış göze çarpmaktadır. En yoğun ve düzenli yapıya sahip kaplama M25 kodlu numunede elde edilmiştir. Elde edilen kaplamaların fiber boyuna ve kesit morfolojileri dikkate alındığında, tüm numunelerde küresel adacıklı yapıların elde edildiği belirtilebilir. 
Üretilen filmlerin fotokatalitik aktivetelerinin tespit edilebilmesi için, zaman bağlı derişim değişimleri UV-vis spektrofotometre kullanılarak tespit edilmiştir. Her üç film için de $30 \mathrm{~mL}$ hacimde, başlangıç derişimi 2,28.10-6 $\mathrm{M}$. olan metilen mavisi çözeltileri fotokatalitik reaktörde parçalanmış ve zamana bağlı derişim değişimi tespit edilmiştir.

Tüm numuneler için zamana bağlı derişim değişimleri Şekil 3.'de yer almaktadır. Elde edilen doğrusal değişimden de anlaşılacağı gibi gerçekleşen fotokatalitik reaksiyonlar 1 . derece reaksiyon kinetiğine sahiptirler ve bu doğruların eğimleri parçalanma hızlarını vermektedir. Tablo 1.'de kinetik eğrilerinden elde edilen reaksiyon hızları listelenmiştir.
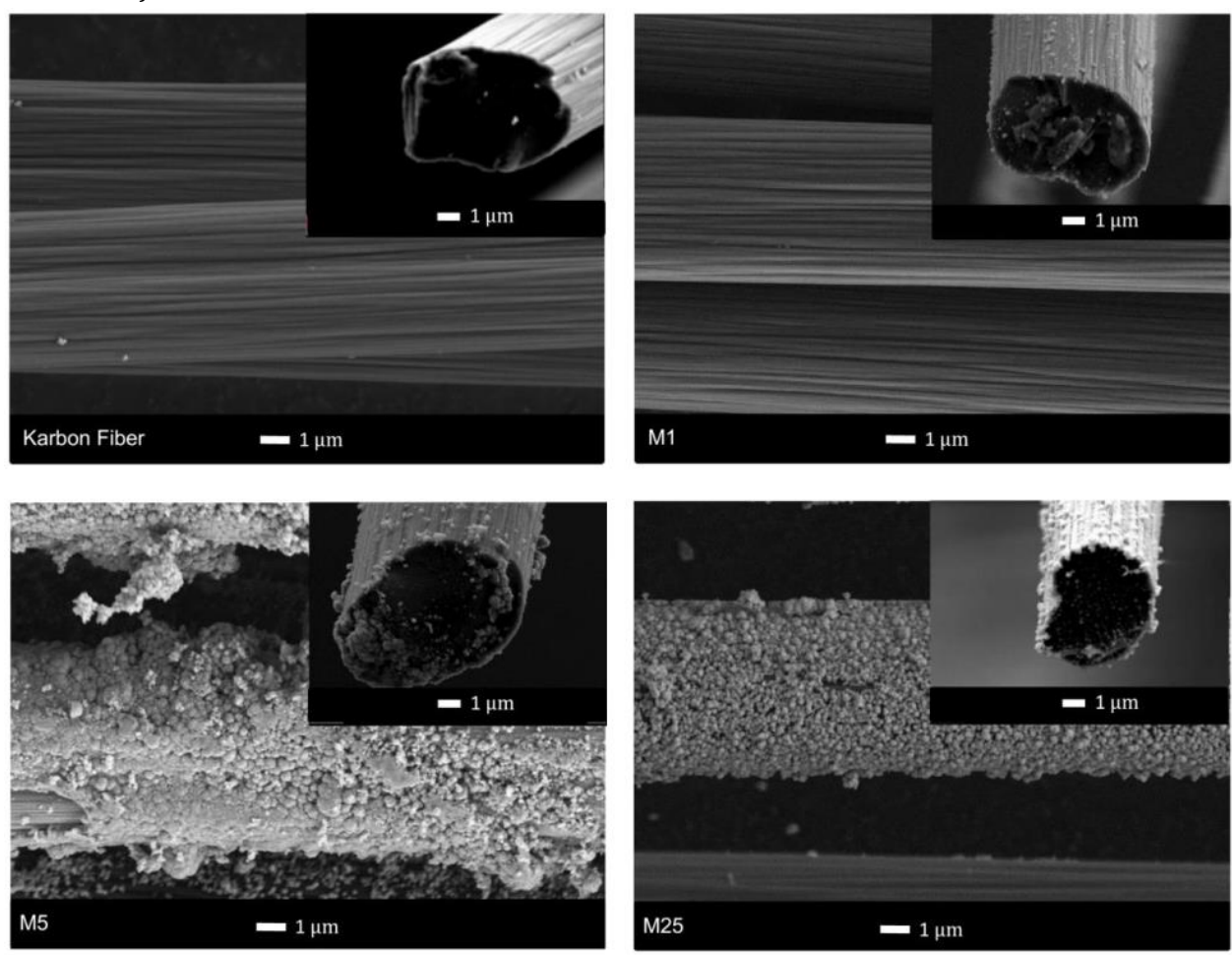

Şekil 2. Karbon Fiber/ZnO numunelerin boyuna ve kesit morfolojileri.
Elde edilen fotokatalitik sonuçlar, XRD ve SEM sonuçları ile büyük ölçüde örtüşmektedir. En iyi kristalinite ve en homojen kaplama özelliklerine sahip yapı olan M25 kodlu fotokatalizör en iyi aktiviteyi sergilemiştir.

M25 kodlu katalizör bulunmadan gerçekleşen (referans) parçalanma ile karşılaştırıldığında geliştirilen katalizörün tepkime verimini yaklaşık olarak 3,6 kat artırdığı tespit edilmiştir.

Tablo 1. Fotokatalitik tepkime kinetikleri

\begin{tabular}{|c|c|c|}
\hline Numune & Hiz Sabiti, $\mathrm{k},\left(\mathrm{sa}^{-1}\right)$ & $\mathrm{R}^{2}$ \\
\hline Referans & 0,39 & 0,964 \\
\hline M1 & 1,07 & 0,992 \\
\hline M5 & 1,27 & 0,994 \\
\hline M25 & 1,39 & 0,995 \\
\hline
\end{tabular}

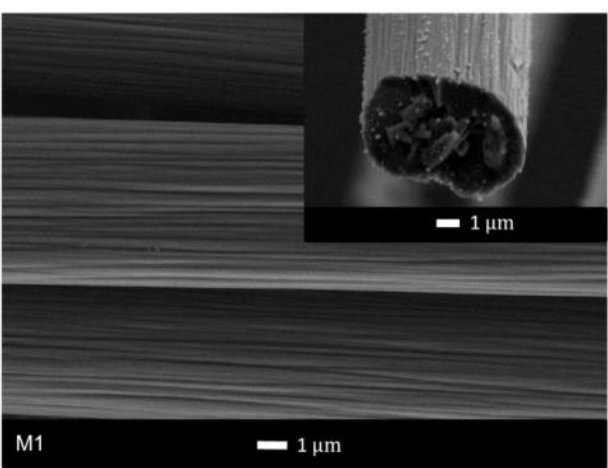




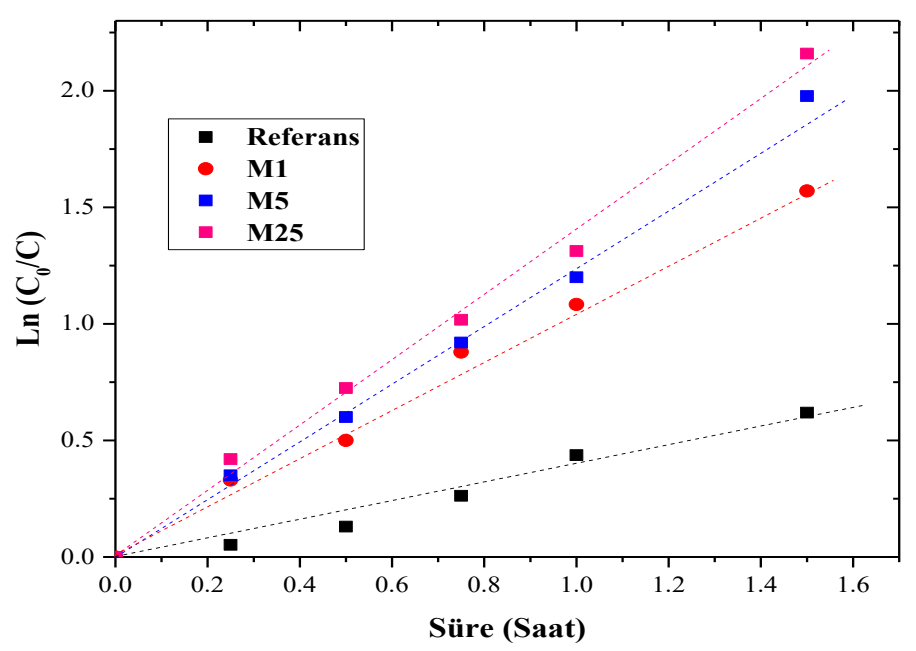

Şekil 3. Karbon Fiber/ZnO numunelerin fotokatalitik tepkime kinetikleri.

\section{Tartışma ve Sonuç}

$\mathrm{Bu}$ çalışmada, karbon fiber/ZnO fotokatalizörler başarılı bir şekilde üretilmiștir. Başlangıç çözelti molaritesinin film morfolojisi, kristal yapı ve fotokatalitik özelliklere etkisi incelenmiştir. Her üç derişimde de kristal yapılı $\mathrm{ZnO}$ filmler karbon fiber üzerinde elde edilmiştir. Başlangıç çözleti molaritesi arttıkça, film yoğunluğu ve homojenitesi artmıştır. Derişimin artması sürekli film üretimini sağladığı gibi fotokatalitik reaksiyon hızlarının da artmasını sağlamıștır.

Son olarak, geliștirilen yapı esnek karbon fiber altlık sayesinde pratik birçok fotokatalitik uygulamada umut vadeden bir malzeme olarak değerlendirilebilir. $\mathrm{Bu}$ yapının farklı modifikasyonları ve yüzey morfolojilerinin geliştirilmesi gelecekte daha etkin katalizörlerin üretilmesi açısından önerilebilir.

\section{Teşekkür}

$\mathrm{Bu}$ çalışmanın deneysel ve karakterizasyon aşamalarındaki yardım ve desteklerinden dolayl Dr. Metin Yurddaşkal ve Saadet Güler'e teșekkür ederim.

\section{Kaynakça}

[1] Fujishima A., Honda K., 1972. Electrochemical photolysis of water at a semiconductor electrode, Nature, Cilt. 238, s.37-38. DOI: $10.1038 / 238037 \mathrm{a} 0$

[2] Alessandro D. M., Maria E. F., Vittorio P., Giuliana I., 2017. ZnO for application in photocatalysis: From thin films to nanostructures, Materials Science in Semiconductor Processing, Cilt. 69, s. 44-51, DOI:10.1016/j.mssp.2017.03.029.

[3] Yun Z., Zhiming P., Xinchen W., 2013. Advances in photocatalysis in China, Chinese Journal of Catalysis, Cilt 34, s.1872-2067. DOI:10.1016/S18722067(12)60548-8.

[4] Kezhen Q., Bei C., Jiaguo Y., Wingkei H., 2017. Review on the improvement of the photocatalytic and antibacterial activities of $\mathrm{ZnO}$, Journal of Alloys and Compounds, Cilt. 727, s. 792-820. DOI:10.1016/j.jallcom.2017.08.142

[5] Asma T., Wiem B., Brigitte S., Ahmed A., Habib E., Mokhtar F., Rabah B., 2017. Structural and optical 
properties of $\mathrm{Na}$ doped $\mathrm{ZnO}$ nanocrystals: Application to solar photocatalysis, Applied Surface Science, Cilt 396, s. 1528-1538. DOI: 0.1016/j.apsusc.2016.11.204. DOI:10.1016/j.mssp.2017.03.029.

[6] Huan W., Xueqing Q., Ruisheng Z., Fangbao F., Yong Q., Dongjie Y., 2017. One-pot in-situ preparation of a lignin-based carbon/ZnO nanocomposite with excellent photocatalytic performance, Materials Chemistry and Physics, Cilt. 199, s.193-202. DOI:10.1016/j.matchemphys.2017. 07.009.

[7] Migyeong K., Wan K. J., 2017. Purification of aromatic hydrocarbons using Ag-multiwall carbon nanotube-ZnO nanocomposites with high performance, Journal of Industrial and Engineering Chemistry, Cilt 47, s.94-101, DOI:10.1016/j.jiec.2016.11.018.

[8] Seongpil A., Bhavana N. J., Min W. L., $\mathrm{Na}$ Y. K., Sam S. Y., 2014. Electrospun graphene-ZnO nanofiber mats for photocatalysis applications, Applied Surface Science, Cilt. 294, 2014, s. 24-28 DOI:10.1016/j.apsusc.2013.12.159.

[9] Darvishi C. S., Rezaee A., Khataee A.R., Safari M., 2014. Photocatalytic process by immobilized carbon black/ZnO nanocomposite for dye removal from aqueous medium: Optimization by response surface methodology, Journal of Industrial and Engineering Chemistry, Cilt 20, s. 1861-1868, DOI:10.1016/j.jiec.2013.09.003.

[10] Yanru Z., Jianzhong M., Junli L., Yan B., 2017. Synthesis of fireworksshaped $\mathrm{ZnO}$ /graphite-like carbon nanowires with enhanced visiblelight photocatalytic activity and anti-photocorrosion, Colloids and Surfaces A: Physicochemical and Engineering Aspects, Cilt 518 s. 57-
63, DOI:10.1016/j.colsurfa.2016.12.05 0.

[11] Junfeng M., Wenfeng F., Yongqiang M., Zhiqiang Y., Shan C., Bingbing N., 2016. Electrochemical growth of $\mathrm{ZnO}$ coating on carbon fiber, Materials Chemistry and Physics, Cilt 171, s. 22-26, DOI:10.1016/j.matchemphys.2015. 12.068.

[12] Demirci S., Yurddaskal M., Dikici T., Sarığlu C., 2018. Fabrication and characterization of novel iodine doped hollow and mesoporous hematite (Fe203) particles derived from sol-gel method and their photocatalytic performances, Journal of Hazardous Materials, Cilt 345, s. 27-37, DOI:10.1016/j.jhazmat.2017.11.00 9.

[13] Dikici T., Demirci S., Erol M., 2017. Enhanced photocatalytic activity of micro/nano textured TiO2 surfaces prepared by sandblasting/acidetching/anodizing process, Journal of Alloys and Compounds, Cilt. 694, $\mathrm{s}$.

246-252 DOI:10.1016/j.jallcom.2016.09.330

[14] Dikici T., Yildirim S., Yurddaskal M., Erol M., Yigit R., Toparli M., Celik E., 2015. A comparative study on the photocatalytic activities of microporous and nanoporous $\mathrm{TiO} 2$ layers prepared by electrochemical anodization, Surface and Coatings Technology, Cilt 263, s.1-7, DOI:10.1016/j.surfcoat.2014.12.07 6. 